\title{
Incorporation of LEED criteria into architectural design process: a strategy to increase construction quality
}

\author{
J. F. Fandino ${ }^{1}$, D. Castro-Lacouture ${ }^{2} \&$ D. Arango ${ }^{1}$ \\ ${ }^{1}$ Architectural Degree Program, University of Ibague, Colombia \\ ${ }^{2}$ School of Building Construction, Georgia Institute of Technology, USA
}

\begin{abstract}
This paper deals with the incorporation of LEED criteria (Leadership in Energy and Environmental Design) as didactic strategy in the architectural design process, in order to improve the construction quality from the stages of conception and design. Our purpose is to motivate future architects on the use of alternative energies, interior quality of the buildings, energy efficiency, water consumption, sustainable development of public spaces and urban landscape, and selection of construction materials. This course is part of the advanced cycle of the Architecture degree program at University of Ibague, Colombia, and approaches the relation between design and sustainable construction inside the environmental policies of a globalized world (UNESCO). These policies have special significance in the education of professionals in the 21 st century considering social, economic and environmental aspects. This workshop-based course has theoretical and practical components, with support from information and communication technologies.
\end{abstract}

Keywords: LEED criteria, architectural design process, construction quality.

\section{Introduction}

The professional practice of architecture is concerned with the qualitative development of the built environment and its incorporation to its natural surroundings. The fast transformation of cities, along with the latest economic, social and environmental crisis in our global society influence the way in which the built environment is planned, designed, built, used, furnished, landscaped and 
maintained. The universal mission of Schools of Architecture is to improve theoretical and practical education.

The UNESCO/UIA Charter for Architectural Education has aimed since its beginning to create a global network within which individual and collective experiences of interest groups and professionals can be shared by all, and that it will enhance the understanding of Architectural Education challenges in the contemporary world. The future vision includes improvement in the quality of life, application of technology that respects social, cultural and aesthetic needs of people, sustainable development of natural and constructed environments, and valuation of architecture as property and responsibility for all of us.

Our interest is on relevant and appropriate knowledge of materials used in architecture and initial and future costs of maintenance. In order to promote this approach, we incorporate LEED criteria [1] during the process of architectural design as strategy for construction quality deployment and for the conception of an ecologically sustainable project. Initially we define the Architectural Design Process and LEED Criteria to establish the relation between them.

\section{The architectural design process}

Generally, the methodology of architectural design has two phases: pre-design and design. The design phase consists of the stages of schematic design, preliminary design and design development. The pre-design includes compiling contextual information, defining the topic, applying analysis and critical judgments and formulating strategies of action. Successively, the design phase is developed according to content and complexity of the topic and information gathering that is represented in graphics, illustrations and sketches and three-dimensional images.

Firstly, schematic design constitutes a spatial proposal that brings together main project characteristics as design concepts and programmatic areas. The general locations for functions within the building are considered and graphically represented in diagram form. Simple plans and elevations are produced to represent relationships among spaces and the basic envelope shape. Material options start to become part of the discussion and a target budget is established for the overall project. The initial proposal is defined based on contents, restrictions and requirements formulated in the pre-design phase. The architects create a work plan to outline what will be done and when. An overall design strategy is chosen.

Secondly, the preliminary design includes the specific development of the emplacement and occupation diagram, locations of functions, morphology and materiality of the schematic design. At this stage we decide the characteristics of the functional, formal and structural components, unified in aesthetic languages that give identity and character to the spatial proposal. At this moment, the graphical representation is more defined and carries out specific dimensional information in scales adapted to the level of detail for every urban or architectural proposition. The spatial proposal contains approaches to set out the project and general specifications for the building, structural system, envelope shape and roof forms. An early conceptual plan shows the general layout roughly to scale, while an aerial perspective sketch locating the project on site showing property lines, 
zoning setbacks and contours is used to communicate de proposal. The final preliminary design floor plans are set out using 3D modelling as an aid.

At last but not least, the design development phase is based on the preliminary design. It is developed with more specifics in form, materials, products, etc. These decisions help solidify design issues in preparation for the construction documents. Drawings are typically larger and more accurately drafted than preliminary design. Square footage, areas program and cost are revisited. Finished floor plans are computer drawn and building details from each plan are made. Finished building elevations and sections with their respective construction details are presented. Based on these results architects prepare the necessary drawings, written specifications and technical documents needed by the constructor to price and build the project. These are also documents required to process the building permit. A graphic presentation of the finalized design can include conceptual diagrams, space plans and plans for furnishing, fixtures and equipment, as well as elevations, sections, ceiling plans, 3D drawing, colours, materials and finished submittals, scale models and mock-ups. Multimedia presentations can incorporate all the above elements plus sound and animation. The start of the building management processes is marked once the project stage is defined and approved, though the modifications, reforms and adequacies will be subject to the urban and architectural regulation of every locality.

\section{Leadership in energy and environmental design (LEED) rating systems}

LEED is a set of rating systems for the design, construction, operation and maintenance of green buildings, homes and neighbourhoods. LEED was developed by the US Green Building Council (USGBC) to help building owners and operators to be environmentally responsible and use resources efficiently. LEED [1] promote buildings environmentally friendly, socially equitable and economically viable. The Council is a non-profit organization that is devoted at its foundational level to increasing the use of sustainable and green building practices. LEED has grown up from one standard for new construction to a comprehensive system of interrelated standards covering all aspects of the development and construction process.

LEED is basically a third-party certification program. It is an internationally accepted organization for design, operation and construction of high performance green buildings. This ensures that buildings are environmentally compatible, provide a healthy work environment and are profitable. LEED New Construction buildings are awarded points for sustainability for things like energy-efficient lighting, low-flow plumbing fixtures and collection of water, to name a few. Recycled construction materials and energy efficient appliances also impact the point rating system.

Green buildings [3] create a healthier working environment for staff and tenants, through better air ventilation and more natural daylight. They also reduce waste, conserve energy, decrease water consumption, and drive innovation. Buildings generate up to 35 per cent of all greenhouse gases, 35 per cent of landfill 
waste comes from construction and demolition activities, and 70 per cent of municipal water is consumed in and around buildings [4]. Making buildings greener can have a significant impact on larger environmental goals. The main characteristics of green buildings are energy and water efficiency, better indoor environment health and better living conditions, use of environmentally friendly or sustainable materials, produce less waste, have lesser transportation requirement and protect or restore the habitat [5]. These characteristics result in a reduced environmental impact throughout the lifecycle of the building.

LEED evaluates the environmental performance along the life cycle of a building. It is based on energy accepted resources and environmental principles that allow a reasonable balance between effective known practices, conceptual innovations and new products in the construction industry. It is an autonomous system designed for residential, commercial, institutional construction and new and constructed buildings. The system of certification of buildings is based on the qualification for credits obtained on six chapters that synthesize the concept of green building, e.g., 1. sustainable sites; 2 . water efficiency; 3 . energy and atmosphere; 4. materials and resources; 5. indoor environmental quality; 6. innovations and process of design. LEED certification is a recognized standard for measuring building sustainability. LEED standards cover new commercial construction and major renovation projects, interiors projects and existing building operations. Standards are under development to cover commercial 'core and shell' construction, new home construction and neighbourhood developments.

Certification systems for sustainable construction are a way used by councils of green construction in different countries around the world to transform the built environment, offering an opportunity to address climate change, dependence of fossil fuels and threats to public health. Every Chapter is shaped by prerequisites and credits. The credits are procedures that must be accomplished and justify for obtaining points. The points are obtained when there are fulfilled the prerequisites demanded in every Chapter, additional to achieve any certification is necessary to achieve all prerequisites. A building can be certified depending on different scales of performance, as it is shown in Table 1 - LEED certification systems are voluntary, based in the consensus and directed by the market. The process of weighting credits is based on 100 basis points, 6 possible points on innovation and design and 4 points on regional priority.

Table 1: LEED certifications.

\begin{tabular}{|c|c|}
\hline Points & Certification \\
\hline $26-32$ & Certified \\
\hline $33-38$ & Silver \\
\hline $39-51$ & Gold \\
\hline $52-69+$ & Platinum \\
\hline
\end{tabular}

The LEED performance credit system aims to allocate points based on the potential environmental impacts and human benefits of each credit. The credit allowance process results in a weighted average for each rating scheme based upon 
actual impacts and the relative importance of those impacts to human health and environmental quality. There are parameters for keeping consistency and usefulness to all the classification systems. For instance, all LEED credits are valued with a minimum of 1 point; all the credits are positive and made of entire numbers; all the credits receive only a static weight in every system of classification (i.e. there are no individualized points depending on project location). Each of the performance categories also have mandatory measures for each category. The weighting process will be evaluated on time to incorporate changes in the values granted to different impacts and the types of building, depending on market conditions and scientific knowledge of buildings [6].

\section{Course didactic proposal}

The course 'Architecture and Sustainable Construction' is part of the Urban and Environmental Component of the Architectural Degree Program at University of Ibague, Colombia. It delves into the advance cycle of undergraduate education and aims to provide new ways of accessing sustainable ideas with design references and building models. The main course goal is to understand the relationship between people and buildings, and between buildings and their environment, and the need to relate buildings and the spaces among them to human needs and scale. Hence, an adequate knowledge to balance physical problems and use of technologies to improve the function of buildings is needed, in order to provide them with internal conditions of comfort. Meeting building user requirements within the constraints imposed by cost factors and building regulations is also a real challenge.

This course contributes to the flexibility in the curriculum by using a workshopbased mode of instruction. It can be adapted and updated to the interests of the University, the Architecture Program, our regional environment and to the groups of participants. The 64-hour course is in the advanced cycle of the Architectural Degree Program and has theoretical component and practical components, each of them with support of information and communication technologies (ICT).

The course 'Architecture and Sustainable Construction' approaches aspects related to construction process development and architectural design from the environmental policies of a globalized world, which have special significance in the professional education of architects in the 21 st century, especially on raising awareness of present environmental challenges worldwide. Unsustainable environmental practices pose increasing threats to the Earth's climate, water, forests, biodiversity, food and energy supply, and thus to the foundations of human existence and well-being. The United Nations has been at the heart of the struggle over the future of the earth's environment. Human-made surroundings that provide the setting for human activity, ranging in scale from buildings and parks or green space to neighbourhoods and cities that can often include their supporting infrastructure, such as water supply or energy networks. UN Global Conferences and intergovernmental policy bodies have been major battlegrounds between forces for greater environmental protection and those who oppose rules and 
regulations in the name of free markets and economic growth [2]. Built environments are typically used to describe the field that addresses the design, construction, management, and use of these man-made surroundings as an interrelated whole as well as their relationship to human activities over time. Together, sustainable design and construction may draw participants towards a major comprehension, interaction and projection of a common habitat.

\subsection{Course objectives}

This course intends to promote the development of knowledge, skills, procedure and attitudes to assume the sustainable design and construction processes through the conceptualization, study of methodologies and successful applied cases, by understanding the components of a LEED rating system and the complexity of sustainable development. In this regard, we seek to understand the relation between sustainability and architectural design, to integrate the concept of sustainable construction to architecture and building engineering, to implement and assess sustainable construction benefits in the architecture profession field, and to provide the tools needed to improve the understanding and assessment of results, which allow for diagnosing the incidence of sustainability criteria in an architectural project.

\subsection{Course contents}

The course 'Architecture and Sustainable Construction' is a workshop that lasts 15 face-to-face sessions, with both theoretical and practical components. The first one presents the contents of the LEED system, and in the second, LEED criteria is applied to an existing architectural project to optimize its sustainable performance. In the first part, contents are presented using lectures, readings, research results, and discussions. This allows to approach basic concepts in order to study design problems and sustainable building construction. In the second part, students obtain data, variables and information needed to structure a sustainable building and study design problems on existing buildings, specifically on the basis of the knowledge of LEED requirements, and particularly upon the characteristics of each criteria.

Thematic units within theoretical component include: introduction to sustainable construction, architectural design criteria, project planning and economic feasibility, alternative energy technologies, stakeholder analysis and management, introduction to LEAN construction (no waste construction), alignment with sustainable design and bioclimatic buildings, description of LEED systems and GREEN ADVANTAGE [6], and building life cycle analysis and assessment. Mainly, the course practical component consists on selecting the topic for developing the final project, reviews, recommendations and corrections of preliminary designs, delivery and presentation of documents, and the final project report and presentation. In addition, it includes using HEED [7, 8], and a presentation of the software, BEES [9] and also Autodesk ECOTECT [10]. 


\section{Course results}

During the course, we integrate LEED criteria to different stages of the architectural design process. To accomplish this, we use each LEED credit for weighting variables and alternative possibilities in the decision-making process, which seemingly were turning out in order to be more effective for optimizing the building sustainable performance. The evaluation of an appropriate solution draws on the information collected and presented during the course. The stages of basic scheme, preliminary design and project included necessary information for the assessment of LEED criteria. The project process was evaluated according to the architectural design records and presentations. Documenting the appropriate solution includes the development of detailed graphical information that would allow the construction of the project.

29 students took part in the 2014 summer course. They were distributed in 11 teams, each of which chose a building and produced a report of the project and a final presentation. Building selection was constrained by factors such as facility of access, building size or available information. All selected buildings were dwelling units, single-unit or multi-family residential housing located in urban consolidated environments. Building areas were ranging between 80 to 120 square meters. Figure 1 shows two plans of one of the house buildings selected for analysis.

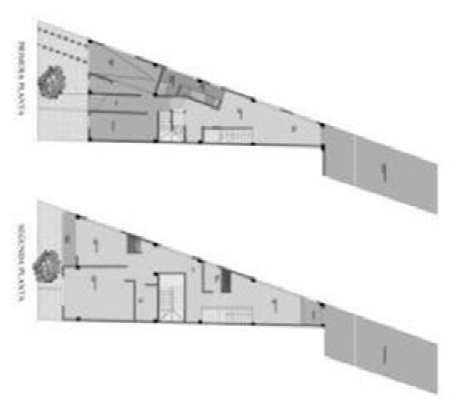

Figure 1: House building selected for analysis.

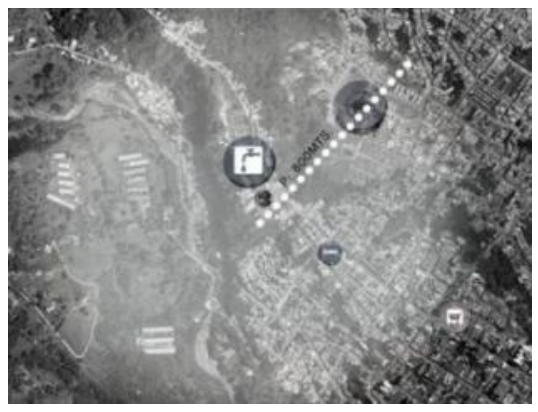

Figure 2: Sustainable site analysis.

Later, each team performed an inventory of the building selected that included: location, surrounding buildings, estimated age of the building, infrastructure, services and facilities available, construction materials used, number and type of bathroom devices, number and type of domestic appliances, and assessment of indoor and outdoor quality of the space. With this general information and the concepts learned in the theoretical component, the teams simultaneously realized a conceptual, critical and systemic approximation of the conditions of the selected 
building, and initiated the process of design for remodelling based on LEED criteria. Figure 3 shows the indoor and outdoor quality of space assessment.

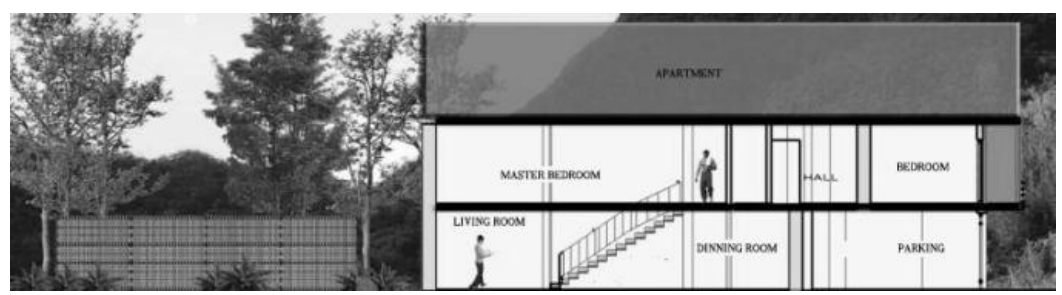

Figure 3: Assessment of indoor and outdoor quality of space.

To start the architectural design process, each team selected the LEED criteria that they had considered to be more appropriate. In all eleven projects, teams selected the 'Sustainable Site' chapter, which has two prerequisites (erosion and sedimentation control plan) and 14 possible credits. From the results obtained, we can infer that this criterion is very important to initiate an architectural design process, and that it should be incorporated to the stage of schematic design in the process. Figure 2 illustrates the characteristics of density analysis and community connectivity on the site selected (5 possible points) on a radius of half a mile (800 meters).

Later in the design process, the most frequent LEED chapters were Water Efficiency (5 possible points), Energy and Atmosphere (17 possible points) and Materials and Resources (13 possible points). These results allowed us to suppose that these credits could be a complement for the stage of preliminary design, for the quantity of specific information that they provide to decision-making process, specially to construction material selection and sustainability criteria.

The software tools HEED and BEES contributed significantly in the decisionmaking process to the analysis of materials and resources. Figure 4 shows some results obtained for the energy analysis of a selected material, and Figure 5 presents the analysis of atmospheric factors in the housing system selected.

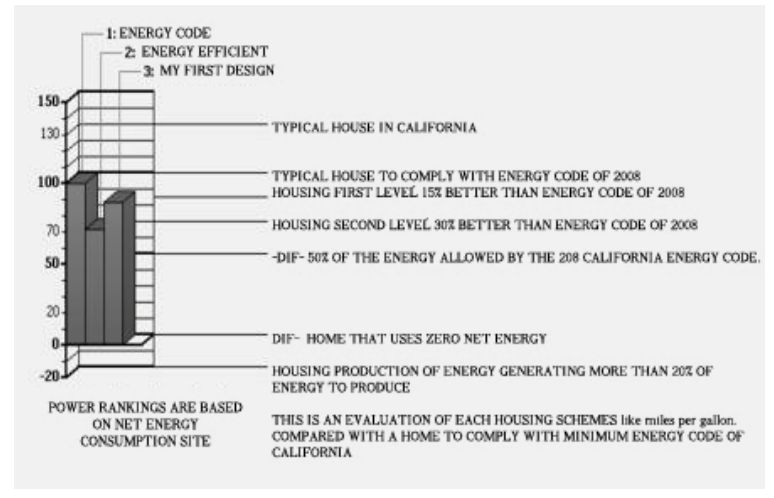

Figure 4: Results of HEED analysis. 


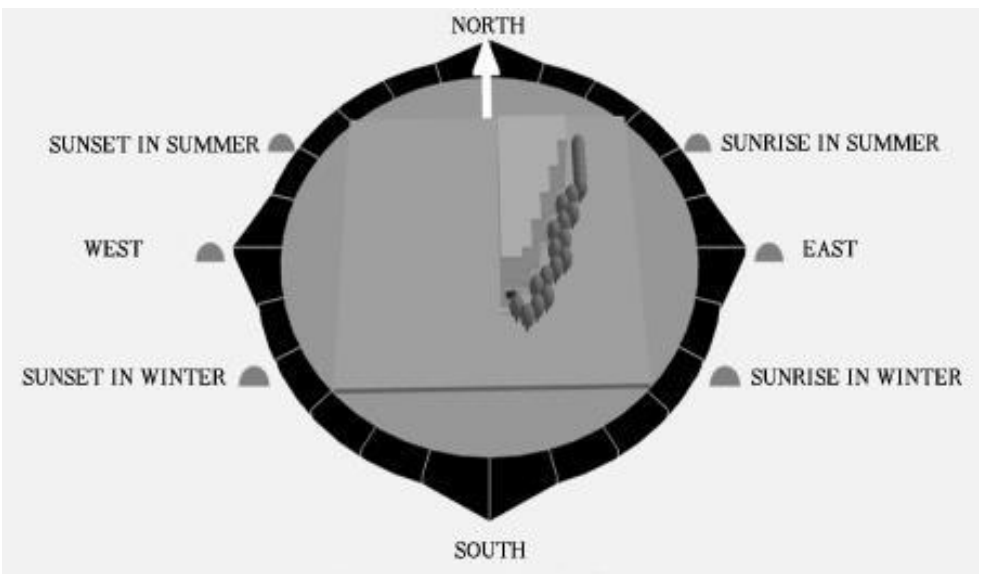

Figure 5: Results of BEES analysis.

At the project stage teams had to re-evaluate the selected criteria and incorporated the Indoor Air Quality (15 possible points). About the credit Design Process (5 possible points), students concluded that it is important to know the concept of Green Construction and the LEED system of certification in order to articulate them to the architectural design process. Table 2 shows the relationship observed between the stages of architectural design and LEED criteria. From our perspective, the knowledge, application and diffusion of this didactic strategy may raise awareness of this issue in architects, thereby motivating them to promote the sustainable construction quality.

Table 2: Relation between stages of design and LEED criteria.

\begin{tabular}{|c|c|c|}
\hline Architectural design stages & LEED chapters incorporated & Possible points \\
\hline Schematic Design & Sustainable Site & 14 \\
\hline \multirow{3}{*}{ Preliminary Design } & Water Efficiency & 5 \\
& Energy and Atmosphere & 17 \\
& Materials and Resources & 13 \\
\hline \multirow{2}{*}{ Design } & Indoor Quality of Space & 15 \\
& Innovations and Design Process & 5 \\
\hline
\end{tabular}

\section{Application of the didactic strategy to a course in the architectural design studio}

After the application of this didactic strategy to the course of architectural design studio in the 10th semester, we were able to establish that the relationship between LEED criteria and architectural design methodology could be articulated to all the phases of the design process. During the second semester of 2014, eight participants who took the course 'Architecture and Sustainable Construction' presented their final project to obtain their architectural degree, at the University of Ibague. The tutor of this architectural design studio was Juan Fandino, professor 
of the Summer School Course, who proposed to all eight students to continue applying the strategies used. In this second opportunity, the Design Studio Course had 16 weeks, with an intensity of 10 hours per week. These conditions allowed for a more detailed follow-up to the incorporation of LEED criteria in the architectural design processes. As we can observe in Figure 6, an analysis of the densities was carried out, as well as of the uses, users, available equipment, public domiciliary services, transport and mobility, and the natural environment. Figure 7 represents the location and distribution of public, common and private spaces proposed according to the LEED criteria, standards and parameters of urban municipal legislation.

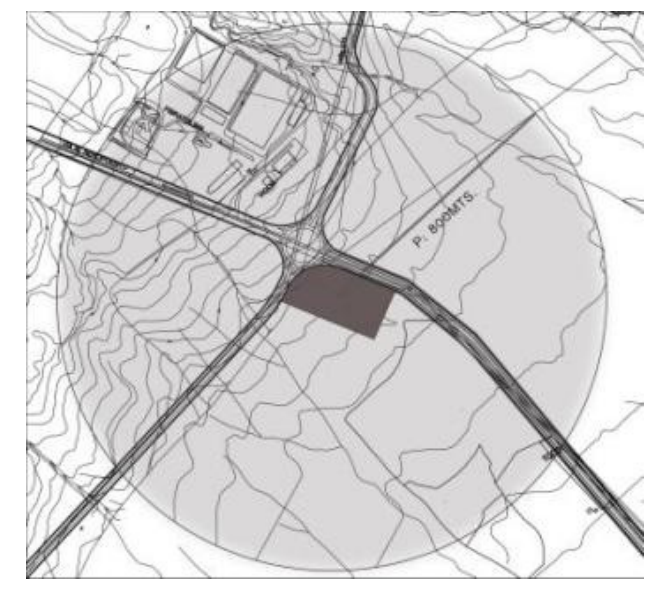

Figure 6: Sustainable site analysis of a final project.

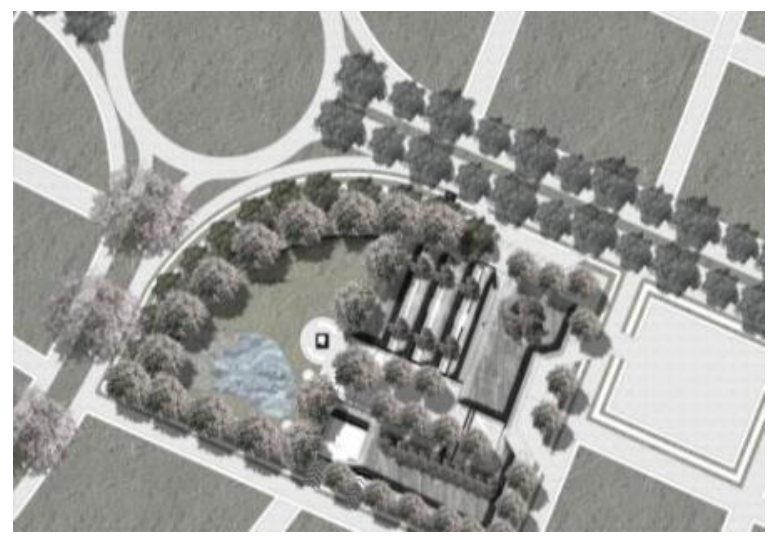

Figure 7: Water, energy and atmosphere efficiency of a final project.

Throughout the course "Architecture and Sustainable Construction" we used a generic distribution of the LEED chapters. In the architectural design studio we were able to consider the credits and make decisions from them, for the whole 
design process. This allowed to not only articulate the design criteria with the LEED parameters, but also to establish new interrelationship dynamics among each of the LEED Chapters. As result, the reports and records that include descriptive, argumentative, proposal and design alternatives for each of the eight indexed projects, presented a high degree of correlation between the design intentions and the formal and technical results of the projects. We can state that these results are in most part a product of the didactic strategy used, while bringing a divergent thought, present in the creative process, and close to the technicalpragmatic thought of technological project resolution.

\section{References}

[1] LEED Green Building Rating System. http://www.usgbc.org/ programs/leed.htm

[2] Sustainable Development Knowledge Platform, https://sustainable development.un.org/

[3] Kruger, A. \& Seville, C. (2013). Green Building: Principles and Practices in Residential Construction (Go Green with Renewable Energy Resources). Delmar, Cengage Learning: New York, 2013.

[4] Canada Green Building Council. http://www.cagbc.org/

[5] Gibson, S. \& Johnston, D. (2008). Green from the Ground Up: Sustainable, Healthy, and Energy-Efficient Home Construction (Builder's Guide): Tauton Press: Newtown, CT, 2008.

[6] US Green Building Council. http://www.usgbc.org

[7] Home Energy Efficient Design - HEED. http://www.energy-design-tools. aud.ucla.edu/heed/

[8] Milne, M. (2007). A Design Tool for Meeting the 2030 Challenge: Measuring CO2, Passive Performance, and Site Use Intensity. Presented at the American Solar Energy Association Conference 2007, Cleveland, Ohio: Rev. 7/13/07.

[9] Building for Environmental and Economic Sustainability - BEES. http://www.nist.gov/el/economics/BEESSoftware.cfm

[10] ECOTEC. http://usa.autodesk.com/ecotect-analysis/ 